(C2007 IEEE. Personal use of this material is permitted. However, permission to reprint/republish this material for advertising or promotional purposes or for creating new collective works for resale or redistribution to servers or lists, or to reuse any copyrighted component of this work in other works must be obtained from the IEEE. 


\title{
TIME DOMAIN ANALYSIS OF A SYNCHRONOUS GENERATOR IN DISTORTED POWER SYSTEMS
}

\author{
M. Ladjavardi M.A.S. Masoum S.M. Islam \\ Curtin University of Technology \\ Department of Electrical \& Computer \\ Engineering, Perth, WA 6845, Australia
}

\begin{abstract}
Calculating the synchronous generator steady state operating conditions and load angle is essential for power system studies. Time and space harmonics can cause variations on power system operation. This paper investigates the impact of time and space harmonics on the synchronous generator inductances, rotor currents, produced stator fluxes and voltages, electromagnetic torque and the steady state rotor angle. Harmonic Domain and abc-frame of reference is used for nonlinear modeling of synchronous generator. The instantaneous electromagnetic torque is calculated using rotational voltage component. Simulation results show that the presence of harmonics can affect the synchronous generator steady state operation and damper windings have considerable impact on the produces stator fluxes and voltages in the presence of harmonics. Matlab/Simulink software and Simpowersystem toolbox are used for the simulation in time domain.
\end{abstract}

\section{Introduction}

With the wide usage of energy-efficient appliances and power-electronic based devices, the presence of current and voltage harmonics in the power system is considerable. On the other hand, stator and rotor windings of synchronous generator contain space harmonics which can also produce and inject time harmonics into the power system particularly in distributed generation (DG) and isolated systems which typically have low inertia and short circuit levels. Therefore, SG operation and system stability studies need to be explored under the influence of harmonics in non-sinusoidal operating environments. In system stability studies, it is necessary to find initial steadystate values of SG variables as a function of nonsinusoidal terminal quantities. Therefore, an accurate nonlinear model of synchronous generator is needed to investigate the steady state operation and stability of the harmonically polluted power systems. However, effects of harmonics on stability of synchronous generators have not been investigated in the literature.

In literatures there are number of linear and nonlinear models of SG. The SG model in qd-frame of reference is the most widely used [1-3]. This model is appropriate for balance sinusoidal operating conditions. A number of SG models have been developed for harmonic analysis [4-7]. These models are based on modified park transformation [5], transient inductances [6], frequency domain including imbalance and saturation effects [7] and abc-frame of reference which can present the nature of time-varying inductances [8]. Harmonic Domain (HD) is widely used for modeling the power system elements [9-16]. The main advantage of using HD is that the linear time periodic systems will be transferred to linear time invariant systems.

In this paper synchronous generator is modeled as a voltage source in harmonic domain and abc-frame of reference considering the impact of damper windings and rotor pole saliency.

Simulation results for SG stator fluxes and voltages, rotor currents, the instantaneous electromagnetic torque and steady state rotor angle show the presence of harmonics can cause variations on the steady state operation. The impact of damper windings is also investigated and it is shown that the damper windings have considerable impact on SG steady state operation in the presence of harmonics. 


\section{Synchronous Generator Model for Non- Sinusoidal Operation}

Synchronous generator is modeled in Harmonic Domain (HD) and abc frame of reference [16]. This model is appropriate for unbalance operating conditions and includes damper windings and rotor saliency. Machine main equations in time domain are as follows:

$$
\left\{\begin{array}{c}
\dot{\psi}_{r}=V_{r}-R_{r} i_{r} \\
\dot{\psi}_{s}=V_{s}+R_{s} i_{s} \\
\psi_{s}=-L_{s s} I_{s}+L_{s r} I_{r} \\
\psi_{r}=-L_{r s} I_{s}+L_{r r} I_{r}
\end{array}\right.
$$

Where $\psi_{r}$ and $\psi_{s}$ are rotor and stator fluxes in time domain respectively. These equations are transferred into harmonic domain:

$$
\left\{\begin{array}{c}
D_{r} \Psi_{r}=V_{r}-R_{r} I_{r} \\
D_{s} \Psi_{s}=V_{s}+R_{s} I_{s} \\
\Psi_{s}=-L_{s s} I_{s}+L_{s r} I_{r} \\
\Psi_{r}=-L_{r s} I_{s}+L_{r r} I_{r}
\end{array}\right.
$$

Where $D_{r}$ and $D_{s}$ are the operational matrices of differentiation applied to the rotor and stator equations respectively. Rotor-self inductance $\left(L_{r r}\right)$ is a constant matrix. $L_{s s}, L_{r r}$ and $L_{r s}$ are self and mutual inductances of stator, rotor and rotor-stator, respectively and are constant Toeplitz-type with the general form of:

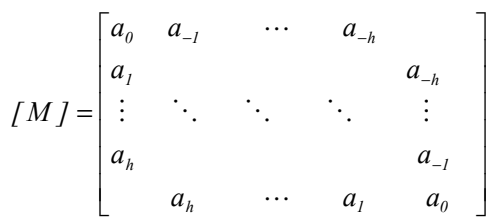

Space harmonics are included in the inductance matrices using abc-frame of reference. The stator $\left(I_{s}\right)$ and rotor currents $\left(I_{r}\right)$ contain fundamental and time harmonics.

\section{Synchronous Generator Operation in the Presence of Time and Space Harmonics}

In this section the SG operation in the presence of time and space harmonics is investigated. The produced stator fluxes and voltages, rotor currents, electromagnetic torque and the rotor angle are calculated in time domain. Space harmonics are considered in the stator-self and stator-rotor mutual inductances and stator currents include time harmonics. It is shown that the there is considerable amount of induced currents on damper windings in the presence of harmonics and they can affect the steady state operating conditions. The simulated synchronous generator characteristics are given in Appendix A.

\subsection{Stator and Rotor Inductances}

Figure 1 illustrates synchronous generator inductances considering space harmonics up to $10^{\text {th }}$ order with the magnitudes of $0.3,0.2,0.1$ and 0.01 of the first and second harmonic order for Rotor-Stator mutual and stator self inductances, respectively.

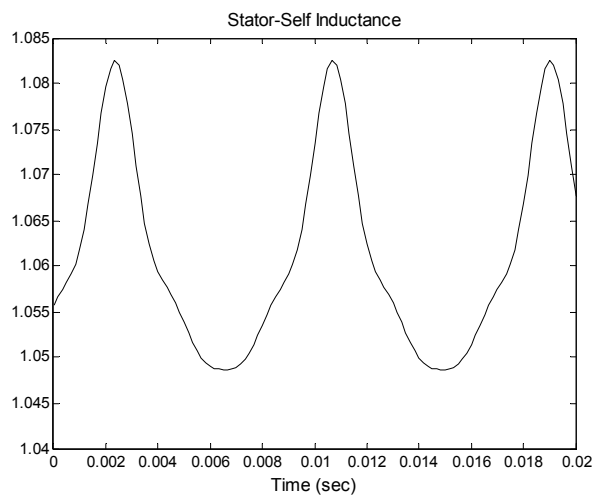

(a)

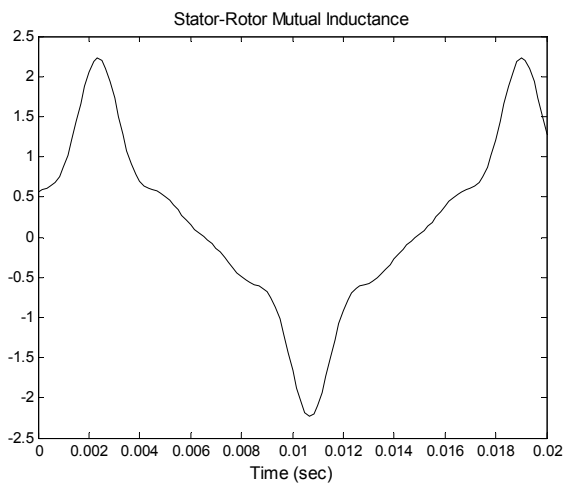

(b)

Figure 1 Impact of space harmonics on (a) StatorSelf Inductance (b) Stator-Rotor Mutual Inductance

\subsection{Rotor Currents}

Time and space harmonics can induce time harmonics in the rotor field and damper windings. These harmonics are of even orders and can be calculated by solving equation 2 in harmonic domain. Figure 2 shows currents in the field and damper windings in sinusoidal and harmonic conditions. These currents in return affect the produced stator fluxes and voltages. 
Space harmonics values are $0.003 \mathrm{pu}, 0.002 \mathrm{pu}, 0.001 \mathrm{pu}$ and 0.0001 and time harmonics are $0.05 \mathrm{pu}, 0.035 \mathrm{pu}$, $0.025 \mathrm{pu}$ and $0.001 \mathrm{pu}$ for the $3^{\text {rd }}$ to $9^{\text {th }}$ harmonics, respectively.

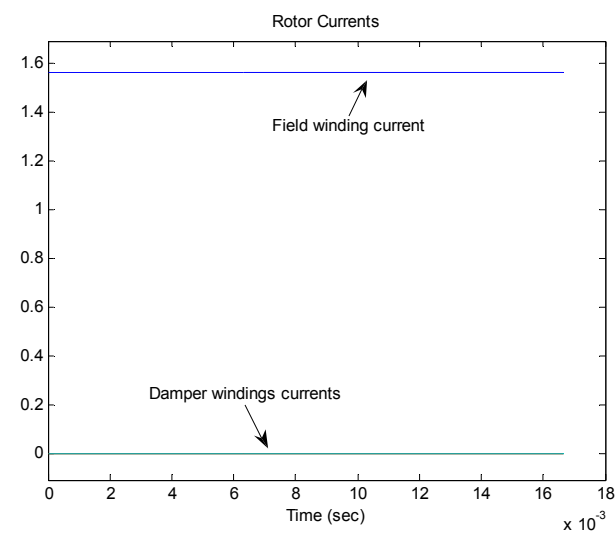

(a)

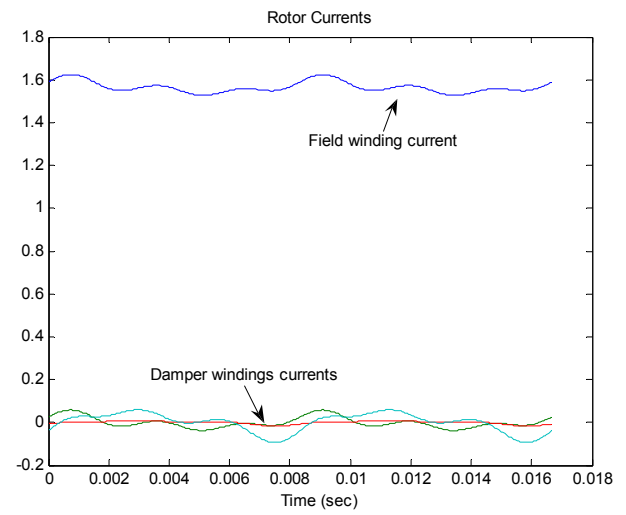

(b)

Figure 2 Rotor currents (a) Sinusoidal conditions (b) in the presence of time and space harmonics

\subsection{Stator Three Phase Fluxes}

Solving equation 2 for stator fluxes, results in additional harmonic components due to interaction between time and space harmonics. The generated stator flux $\left(\psi_{s}\right)$ includes fundamental and harmonic components which may not be balance at three phases. The additional harmonic components produce rotating fields with different speeds with respect to the rotor and hence can not produce constant torques.

Figure 3 illustrates 3-phase stator fluxes with and without damper windings. Time and space harmonics are assumed at the same level as section 3.2.

It is observed that damper windings have considerable impact on the produced stator fluxes and can not be ignored in the harmonically polluted systems.

Harmonics can cause variations on the induced fundamental component of stator flux in SG which will result in addition or reduction of the generated power and hence affect the rotor angle and dynamic behavior of the power system. They can also produce unbalance 3 -phase fluxes in stator windings and inject zero sequence voltage into the system.

Solving equation 2 in harmonic domain and applying Park Transformation on the fundamental component of the stator flux results in the additional components in dq-axis ( $\psi_{d}^{\text {dueto harm }}, \psi_{q}^{\text {dueto harm }}$ ) [17]. The values of the additional components depend on the time and space harmonics at special harmonic orders which contribute in producing forward rotating fundamental stator flux.

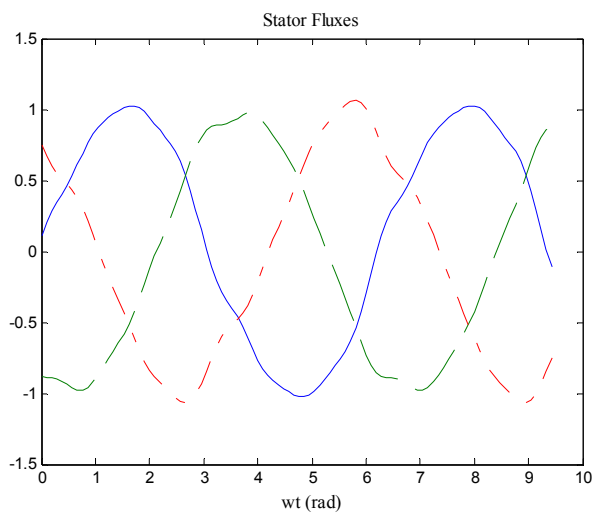

(a)

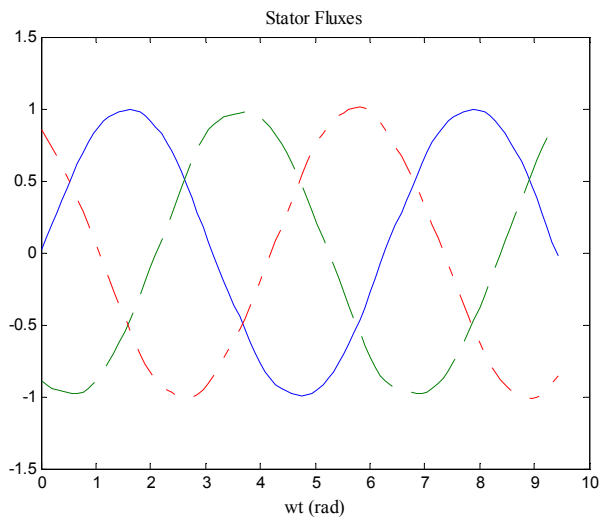

(b)

Figure 3 Three phase stator fluxes in the presence of time and space harmonics, (a) without and (b) with damper windings

\subsection{Produced Stator Three-Phase Voltages}

Figure 4 shows the impact of harmonics on the produced stator voltages. The produced voltage harmonics in stator can propagate in small systems and increase the level of total harmonic distortion. Comparing figures $4 \mathrm{a}$ and $4 \mathrm{~b}$ it is observed that damper windings can affect the quality of the produced voltage. 


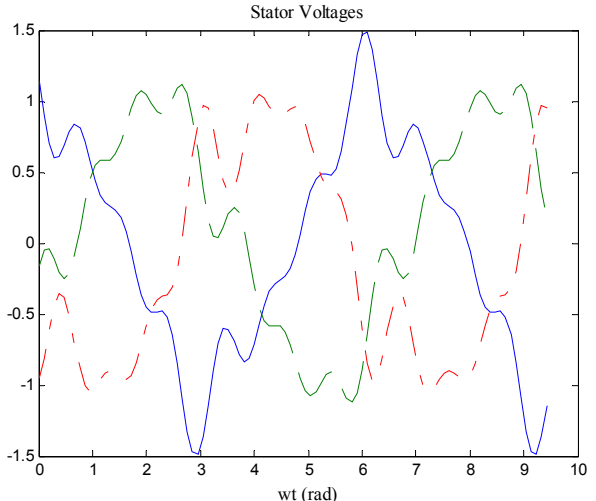

(a)

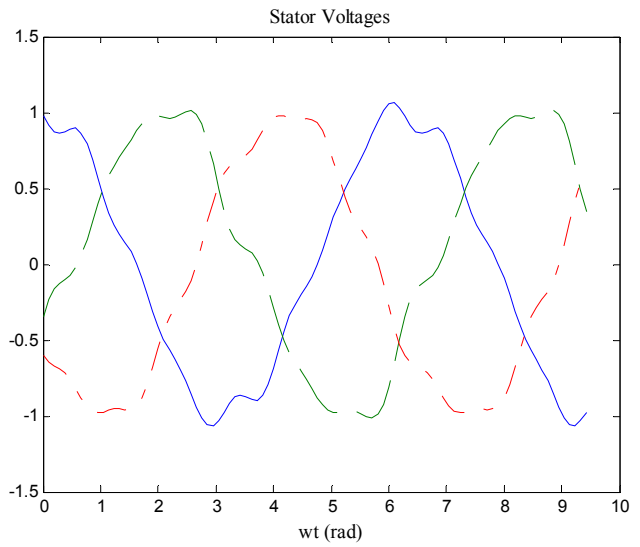

(b)

Figure 4 Three phase stator voltages in the presence of space harmonics, (a) without and (b) with damper windings

\subsection{Electromagnetic Torque}

Electromagnetic torque is related to the instantaneous power flows across the airgap from stator to rotor via the actual rotor speed $\left(\omega_{r}\right)$ by the following equation [18]:

$T_{\text {em }}(t)=P_{\text {em }}(t) / \omega_{r}$

For all polyphase ac machines, the electromagnetic airgap power is defined as the product of the instantaneous rotational voltage component in each armature phase times the instantaneous phase current. Hence, the produced electromagnetic power is calculated using the following equation:

$$
P_{e m}=\hat{e_{a}} \cdot i_{a}+\hat{e}_{b} \cdot i_{b}+\hat{e_{c}} \cdot i_{c}=\hat{E}_{a b c} \cdot I_{a b c}
$$

Where, $e_{a}, e_{b}$ and $e_{c}$ are the rotational phase voltage terms and $i_{a}, i_{b}$ and $i_{c}$ are the stator three-phase currents.

The rotational voltage components are defined as:
$\hat{E}_{a b c}=\dot{L}_{a b c} . I$

Where,

$\dot{L}_{a b c}=d L_{a b c} / d t$

Writing equation 5, for phase (a) as an example, is as follows:

$$
\begin{aligned}
& e_{a}=\left(d L_{a a} / d t\right) i_{a}+\left(d L_{a b} / d t\right) i_{b}+\left(d L_{a c} / d t\right) i_{c}+ \\
& \left(d L_{a F} / d t\right) i_{F}+\left(d L_{a D} / d t\right) i_{D}+\left(d L_{a G} / d t\right) i_{G}+ \\
& \left(d L_{a Q} / d t\right) i_{Q}
\end{aligned}
$$

Similar expressions can be written for $e_{b}$ and $e_{c}$.

Figure 5 demonstrates the instantaneous electromagnetic torque in sinusoidal and harmonic operating conditions considering the impact of damper windings. In figure 5a, the produced torque in sinusoidal system is compared with the one in the presence of space harmonics. It is observed that space harmonics can apply pulsation on the electromagnetic torque.

Figure $5 \mathrm{~b}$ shows that the interaction between time and space harmonics can cause higher electromagnetic torque perturbations.

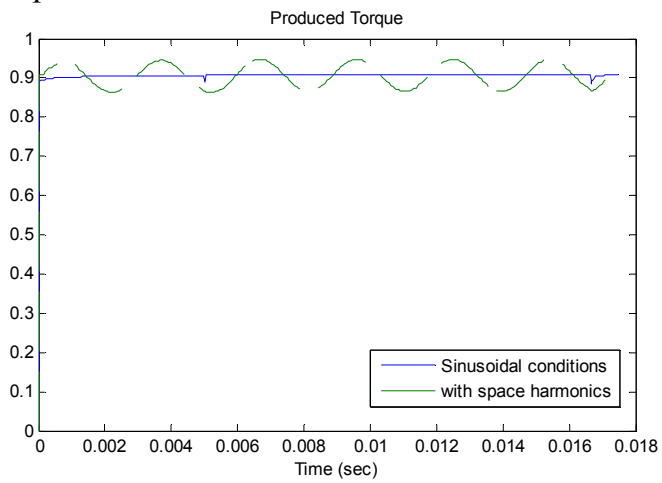

(a)

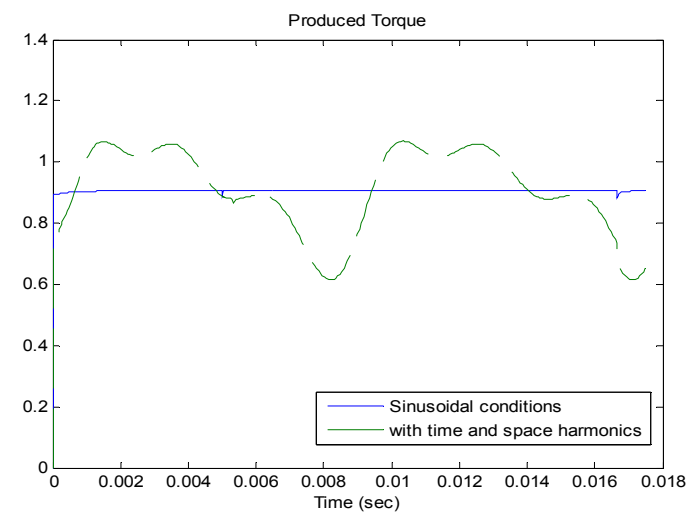

(b)

Figure 5 Electromagnetic torques in the presence of (a) space (b) time and space harmonics 


\section{Load Angle}

Synchronous generator rotor (load) angle, which is one of the most important parameters for power system stability studies, is determined by the active power demand by the load.

For power system studies, it is necessary to compute the initial steady-state load angle of synchronous generator as a function of non-sinusoidal terminal quantities. As it is shown in figure 6, additional terms of stator flux due to harmonics can change the steadystate load angle. The variations on rotor angle are related to the electromagnetic torque via the equation of motion.

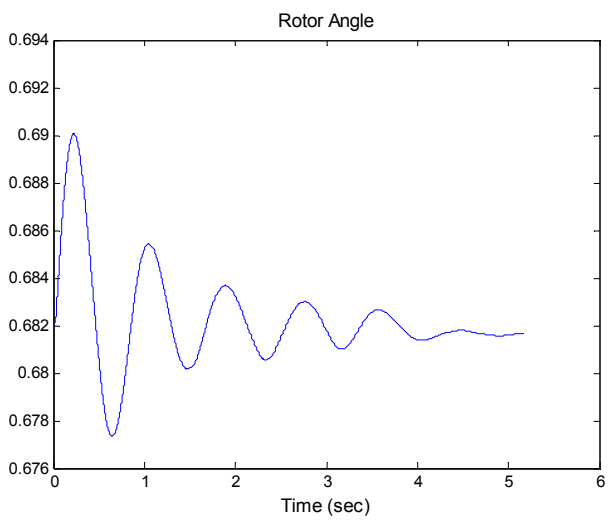

(a)

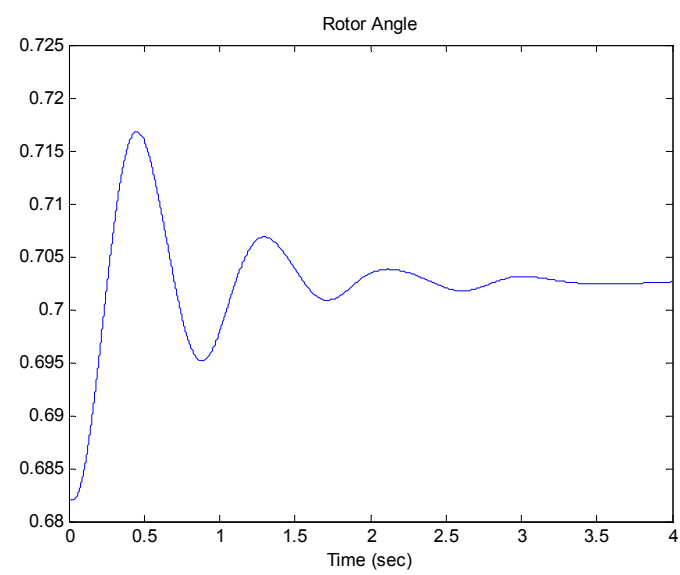

(b)

\section{Figure 6 Rotor angle (a) Sinusoidal conditions (b) in the presence of time and space harmonics}

\section{CONCLUSION}

A nonlinear model of synchronous generator in harmonic domain and abc-frame of reference considering the impact rotor pole saliency and damper windings is used to demonstrate the impact of time and space harmonics on the steady state operation of the SG. Simulation results show the following main contributions:

- Time and space harmonics can cause variations on the produced stator fluxes and voltages.

- SG in the presence of time and space harmonics can produce unbalance stator voltages.

- Induced harmonic currents on damper windings are considerable.

- Harmonics can cause electromagnetic torque perturbation.

- Damper windings have considerable impact on the produced stator fluxes and voltages.

- Time and space harmonics will change the steadystate value of the synchronous generator load angle.

\section{Acknowledgement}

The first author is an endeavor International Postgraduate Research Scholarship supported by the Australian Government and wishes to acknowledge her Postgraduate Scholarship by Curtin University of Technology.

\section{References}

[1] P. Kundur, "Power System Stability and Control", New York: McGraw-Hill, 1994.

[2] J.D Roark, C.A Fross , " Unbalanced synchronous machine analysis using frequency domain methods", Proc. IEEE PES summer meeting, Los Angeles, CA, 1978.

[3] W.W. Xu, H.W. Dommel, J.R. Marti, "A synchronous machine model for three - Phase harmonic analysis and EMTP initialization", IEEE Trans. power Systems, Vol. 6, No. 4, pp. 1530 - 1538, 1991.

[4] P. Rodriguez, A. Medina, "Fast periodic steady state solution of a synchronous machine model incorporating the effects of magnetic saturation and hysteresis", IEEE PES Winter Meeting, Vol. 3, pp. 1431-1436, 2001.

[5] H. Chen, Y. Long, X.P. Zhang, "More sophisticated synchronous machine model and the relevant harmonic power flow study", IEE Proceedings on Generation, Transmission and Distribution, Vol. 146, No. 3, pp. 261-268, 1999.

[6] P.M. Hart, W.J. Bonwick, "Harmonic Modeling of synchronous machine," IEE Proceedings on Electric Power Applications, Vol. 135, No. 2, pp. 52-58, 1988. [7] K.A. Corzine, B.T. Kuhn, D. Sudhoff, H.J. Hegner, "An Improved Method for Incorporating Magnetic saturationin the Q-D Synchronous Machine Model" 
,IEEE Trans. Energy Conversion , Vol . 13 , NO.3, pp.270-275, 1998.

[8] J. Arrillaga, J.G. Campos-Barros, H.J. Al-Kashali, "Dynamic modeling of single generators connected to HVDC converters", IEEE Trans. Power Appar. Syst, Vol.4, pp. 1018-1029, 1978.

[9] J. Arrillaga, A. Medina, M. L. V. Lisboa, M. A. Cavia, P. Sánchez, "The harmonic domain. A frame of reference for power system harmonic analysis", IEEE Trans. Power Delivery, Vol. 10, pp. 433-440, 1995.

[10] E. Acha, "Modeling of Power System Transformers in the Complex Conjugate Harmonic Domain Space", PhD thesis, University of Canterbury, Christchurch, New Zealand, 1988.

[11] J. Rico, E. Acha, and T. J. E. Miller, "Harmonic domain modelling of three phase Thyristor-controlled reactors by means of switching vectors and discrete convolutions", IEEE Trans. Power Delivery, Vol. 9, pp. 1609-1615, 1994.

[12] A. Semlyen, E. Acha, J. Arrillaga, "Newton-type algorithms for the harmonic phasor analysis of nonlinear power circuits in periodical steady-state with special reference to magnetic nonlinearities", IEEE Trans. Power Delivery, Vol. 3, pp. 1090-1098, 1988.

[13] E. Acha, A. Semlyen, N. Rajakovic, "A harmonic domain computational package for nonlinear problems and its application to electric arcs", IEEE Trans. Power Delivery, Vol. 5, pp. 1390-1397, 1990.

[14] J.J. Rico, M. Madrigal, E. Acha, "Dynamic harmonic evolution using the extended harmonic domain", IEEE Trans. Power Delivery, Vol. 18, No. 2, pp. 587-594, 2003.

[15] A. Medina, J. Arrillaga, J.F. Eggleston, "A synchronous machine model in the harmonic domain", Proc . Int . Conf . on Electrical Machines, pp. 647-651, UK, September 1992.

[16] A Ramirez, A. Semlyen, R. Iravani, "Harmonic domain characterization of the resonant interaction between generator and transmission line", IEEE Trans. Power Delivery, Vol., No. 2, Part 2, pp. 1753-1762, 2005.

[17] M. Ladjavardi, M.A.S. Masoum, S.M Islam, "Small-Signal Stability Analysis of Distorted Power Systems installed with SSSC", IEEE Power Engineering Society General Meeting, pp. 1-6, 24-28 June 2007.

[18] N.A. Demerdash, T.W Nehl, "Electric machinery parameters and torques by current and energy perturbations from field computations. II. Applications and results", IEEE Trans. Energy Conversion, Vol. 14, No. 4, pp. 1514 - 1522, 1999.

\section{Appendix A}

Synchronous machine parameters in per unit of machine rating $(555 \mathrm{MVA}, 24 \mathrm{kV}, 0.9 \mathrm{p} . \mathrm{f}, 60 \mathrm{~Hz}$, 3600RPM turbine generator) are:

- Stator Parameters:

$$
L_{s}=1.060 \quad L_{m}=0.0140 \quad M_{s}=0.4550 \quad R_{a}=0.003
$$

- Rotor Parameters:

$$
\begin{array}{llc}
R_{F}=0.0006 & L_{F}=1.551 & L_{F D}=1.386 \\
R_{D}=0.0284 & L_{D}=1.5573 & L_{G Q}=1.344 \\
R_{G}=0.00619 & L_{G}=2.0692 & L_{F G}=L_{F Q}=L_{D G}=L_{D Q}=0 \\
R_{Q}=0.02368 & L_{Q}=1.469 . & \\
\hline
\end{array}
$$

- Stator Rotor Mutual Parameters:

$$
M_{F}=M_{D}=1.386 \quad M_{G}=M_{Q}=1.344
$$

